\title{
Risk, Crisis, and Social Media
}

\author{
A systematic review of seven years' research
}

\author{
Joel Rasmussen \& Øyvind Ihlen
}

\begin{abstract}
The literature on social media use in risk and crisis communication is growing fast, and it is time to take stock before looking forward. A review of 200 empirical studies in the area shows how the literature is indeed increasing and focusing on particular social media platforms, users, and phases from risk to crisis relief. However, although spanning 40 countries, a large proportion of the world's social media users are under-represented in the research. In addition, little attention is given to the question of who is actually reached through social media, and the effects of the digital divide are rarely discussed. This article suggests that more attention is given to the questions of equal access to information and ICTs, complementary media channels, and cultural diversity.
\end{abstract}

Keywords: social media, risk communication, crisis communication, research review, research trends, digital divide, geographical focus, social media choice, social media users

\section{Introduction}

Social media has received considerable attention from researchers in risk and crisis communication. However, as the number of studies on social media, risk, and crisis communication has grown tremendously, it becomes all the more important to take stock before moving forward to avoid exhausting research questions and topics. While a few useful literature reviews have been published (e.g., Fraustino, Liu \& Jin 2012; Ruggiero \& Vos 2014; Veil, Buehner \& Palenchar 2011), these must be updated and expanded, not least to include the recent experimental and comparative studies, and cover the field's geographical focus. We thus review recent research and draw out some important conclusions. In particular, we argue that researchers and risk and crisis planners must take into account that not everyone uses social media. Particularly, citizens with low socio-economic status are those with the lowest internet availability (Zickuhr 2013), and they are also the most vulnerable in a disaster, which Hurricane Katrina tragically proved (Thiede \& Brown 2013). Risk and crisis management via social media thus risks missing those who are most vulnerable and most in need of relief information.

The article is structured as follows: next, we define social media and its integration with risk and crisis communication. This section is followed by a discussion of 
previous literature reviews, and leads up to the formulation of our research questions. The following section on methodology describes how we conducted a database search and coded the resulting sample. Our findings are then presented in a section structured after the main variables. The findings and their implications are then discussed in the conclusion.

\section{Defining risk, crisis, and social media}

Researchers in the fields of risk and crisis management have increasingly come to conceptualise risk and crisis as transboundary (e.g., Boin, Rhinard \& Ekengren 2014; Falkheimer 2013; Olsson 2015), meaning that the origins and effects of threats and adverse events traverse functional, national, and cultural boundaries. Acknowledging the need for concepts that are useful in such complex processes, we rely on Klinke and Renn (2002) who see risk as the "possibility that human actions or events lead to consequences that harm aspects of things that human beings value" (p. 1071). This definition does not presuppose that risk is a given object. Hilgartner (1992) adds a communicative perspective on such risk objects. He states that "changes in the definition of risk objects can redistribute responsibility for risks, change the locus of decision making, and determine who has the right - and who has the obligation - to 'do something' about hazards" (Hilgartner 1992: 47). Therefore, risk is not just something we communicate about. It is defined, negotiated, and shaped through communication.

Following this definition of risk, we conceptualise crisis as a variety of severe events negotiated through communication. Crisis is defined by Boin et al. (2005: 2-3) as situations where widely shared values are under immediate threat, leading both to demands for prompt action and to uncertainties regarding the full extent and consequences of the event and possible remedies.

Approaching risk and crisis as transboundary phenomena entails the bridging of relations that are somehow tied apart. Research has particularly drawn attention to the limitations in understanding risk and crisis within the confines of the nation state. Threats and adverse events increasingly develop and have effects across nations and their political and jurisdictional mandate, necessitating cooperation across nations and sectors (e.g., Olsson 2015). Whereas these limitations of a national perspective are widely recognised, we suggest that there are more boundaries - surfacing at the local or global level - that transboundary risk and crisis communication should take into account. In general terms, a boundary entails relations marked by similarity and difference. This article stresses some boundaries, including differences in social media access and use, and the partial geographical scope of the field.

We approach social media as web-based platforms whose key applications offer opportunities for users to communicate and maintain social relationships with multiple individuals. The most optimistic accounts of social media convey that platforms such as Facebook, Twitter and YouTube offer anyone with necessary knowledge and Internetaccess the opportunity to engage in many-to-many dialogue across the globe (Hogan \& Quan-Haase 2010). Nevertheless, empirical studies show strong patterns of homophily in social media, in that elites follow elites whereas "ordinary" citizens rarely get attention. Wu et al. (2011) demonstrate that 50 per cent of the consumed content on Twitter was produced by 20000 elite users. 
With these limitations in mind, social media still offers a range of possibilities for risk and crisis communication. Among examples mentioned in the literature is the ability to facilitate information and opinion sharing, but also to engage in dialogue with and build relationships with key stakeholders. Initiating dialogue before risks manifest and/ or crises occur can help an organisation navigate a crisis (Veil, Buehner \& Palenchar 2011). Listening in on the conversations that take place on social media is also valuable for organisational issues management, here defined as the attempt by an organisation to map important themes, trends or problems that in the long run represent a threat to the organisation (Heath \& Palenchar 2008). Social media analysis can assist organisations in identifying and understanding issues that might eventually rise to prominence. By addressing these issues early on, organisations might be able to avoid the issue evolving into a full-blown crisis. Social media can also help empower relevant members of the public to develop and use emergency responses so that crisis outcomes can be mitigated (Palenchar 2009). Using social media in crisis communication may also prove more favourable among stakeholders than issuing press releases via traditional media ( $\mathrm{Xu}$ \& Wu 2015).

\section{Literature reviews on the topic}

Previous literature reviews have typically focused on developing best practices. In their review, Veil, Buehner and Palenchar (2011) formulate advice for how organisations should establish policies, prepare pre-event logistics, and partner with the public as well as authoritative sources. Other suggestions relate to crisis response, such as meeting the needs of the media, communicating with compassion and empathy, and accepting uncertainty and ambiguity. Furthermore, messages of self-efficacy should be provided. Following the hurricanes "Katrina" and "Rita", volunteers created a people-finder blog that helped blog-users finding missing relatives and friends. After the Haitian earthquake, volunteers organised donations via Twitter (Smith 2010). A particularly interesting point to us was that Veil, Buehner and Palenchar (2011) found little discussion of difference in access to technology. The latter has been dubbed "the digital divide" and can be said to encompass three distinct aspects, namely a global, social, and democratic divide. The former refers to differences in access to technology, the second concerns how a population can be seen as information rich or poor, while the last aspect relates to differences in the use of digital media to partake in public life (Norris 2001).

The literature review of Fraustino, Liu and Jin (2012) concludes that that there is substantial evidence that social media use increases during disasters (see Sweetser \& Metzgar 2007), and that media choices are crucial - Twitter being ideal for quick, short, news updates (see Schultz, Utz \& Göritz 2011). Repeatedly, however, they find that the studies for the most part focus on single cases and single media - mostly Twitter - but results are taken to represent social media in general. Moreover, Fraustino, Liu and Jin (2012) point out that there are several types of social media users, ranging from those who only take part in information without ever writing or sharing a post ("lurkers"), to those who have thousands of followers and sometimes even organise public events via social media during crises (Jin \& Liu 2010; Paine 2007). They have various reasons for using social media during crises, such as information retrieval (Jin, Liu \& Austin 2014), connecting with family and friends (Procopio \& Procopio 2007), and also stress-relieving 
humour (Liu, Jin \& Austin 2013). Importantly, we also know that some people do not use social media because of issues with privacy and security (Yates \& Paquette 2011), and doubts about medium and source credibility and information accuracy (Veil, Buehner \& Palenchar 2011). Fraustino, Liu and Jin (2012) argue that most of the research has been descriptive, and call for investigations of causal relationships that can guide best practices.

Ruggiero and Vos (2014) focused on monitoring in crisis communication, and found that most of the research discussed the use of YouTube, with Twitter and blogs trailing behind. Given its popularity, it is notable that Facebook was not studied. The authors synthesise and present advice regarding, for instance, how practitioners should look for the communication patterns of emerging networks, such as how a network is developed from a tweet via re-tweets, or a blog post that is shared multiple times on social networking platforms.

The present study will comprise a comprehensive quantitative content analysis, since the above literature reviews do not cover volume trends (e.g., Alexander 2014; Fraustino, Liu \& Jin 2012; Veil, Buehner \& Palenchar 2011), or only include a limited number of studies (e.g., Ruggiero \& Vos 2014).

Firstly, it has been postulated both that the field is growing (Austin, Liu \& Jin 2012), and that "it is still quite limited" (Alexander 2014: 719). Yet another study states that research on crises and social media peaked, quantitatively speaking, in 2009-2010 (Simon, Goldberg \& Adini 2015). Our first research question, therefore, is:

1) What is the volume trend regarding research on social media and risk/crisis communication?

There are indications that most of the research in this field rather focuses on "relief and rehabilitation than on risk reduction" (Gender and Disaster Network 2008). Another study criticizes the fact that the field is lacking experimental data (Fraustino, Liu \& Jin 2012). Hence, our second research question is:

2) To what extent is the field drawing lessons from risk/pre-crisis situations, crisis situations, or experimental, fictitious scenarios?

It is important to note which platforms the research on risk and crisis addresses, as people of different generations use different social media (Bowe \& Wohn 2015) and platform popularity fluctuates. We need to be aware that some of today's social media may soon be yesterday's technology. Our third research question, therefore, is:

3) What is the trend in terms of social media platforms that the research focuses on?

We know that public relations research has mainly focused on the corporate sector (Olsson 2014), but we have little knowledge of which actors and organisations the research on risks, crises, and social media addresses. Hence, our fourth research question is:

\section{4) Which groups of social media users and/or case organisations are studied?}

Communication theory and research were long developed in Europe and the US, and much less so in other parts of the world. Gunaratne (2009) stresses that the power imbalance within global academia - including media and communication studies - has been as uneven as in the sectors explained in Wallerstein's world systems theory. So, 
although risks and crises are part of lived experience across the globe, and social media use is expanding fast (Kemp 2015), there may be a Western bias in terms of attention paid to certain regions. We therefore pose the following research question:

\section{5) Where are the empirical studies geographically focused?}

Following up on RQ5, we are also compelled to address how the research speaks to issues of ICT and social media access (cf., Mossberger, Tolbert \& Stansbury 2013). Hence, our final research question is:

6) Do the studies mention the digital divide or other issues of social media access?

\section{Methodology}

To answer the research questions, the lead author searched for peer-reviewed articles listed in the databases Communication and Mass Media Complete (CMMC) and Summon, rendering suitable results in 106 English language journals (see Appendix). We assumed that the field is wider than the discipline of media and communication studies. For example, we included articles from informatics and computer science journals if they were about social media content and users, and from health science journals if they dealt with collective risks and crises, such as epidemics, and social media. The following keywords were applied for the period 2009-2015: internet, online, social media, Facebook, Twitter, YouTube, blog*, or Instagram; all of which were combined with risk*, crisis, or disaster*.

Our methodology is best described as a systematic review, in that it includes an exhaustive search and systematisation of several research characteristics in studies that deal with a common theme, but which may be quite heterogeneous in design and focus. Select results are explained in narrative form. This contrasts another form of review, the meta-analysis, which statistically combines the results of studies that are homogenous in design and focus (Grant \& Booth 2009).

To retain some similarity and comparability, book reviews, editorials, or theoretical articles without empirical data were excluded from the final sample, along with articles that did not treat social media and risk or crisis as central themes. An exclusion criterion was whether the study could have been carried out, presented, and understood without the dimension of social media and risk or crisis. The final sample consisted of 200 articles, with Public Relations Review taking the lead with 27 published pieces. Content analysis (Krippendorff \& Bock 2008) was performed on these articles, with coding of six variables: 1) publication year; 2) whether the main focus is on real life risks, crises, or fictitious cases; 3) social media platform(s) studied (Twitter, Facebook, blogs, YouTube, message boards, Instagram/Flickr, wikis, other); 4) whose social media use is studied (citizens, public institutions, students, journalists, business organisations, NGOs, public relations practitioners, universities/colleges, other); 5) which geographic area the data is drawn from; and, 6) whether or not the studies mentioned the digital divide or related issues of ICT access. For variable 5 we used the same geographical units as the We Are Social reports (e.g., Kemp 2015).

After an initial round of coding, the codebook was improved. The lead author then coded 150 articles, while a research assistant coded 80, allowing for an intercoder reli- 
ability test regarding 15 per cent of the articles $(n=30)$. Using Krippendorff's alpha, the result was .92 and above for each variable, which must be deemed satisfactory. Almost exclusively, the study used nominal variables. In order to identify trends over time, a multiple variable approach was employed (Riffe 2014). The use of a total sample strategy rendered no need for calculating statistical significance.

\section{Results}

\section{Volume}

Not surprisingly, the results show that the number of studies on social media, risk, and crisis communication is increasing. Since social media use is increasing (e.g., Duggan et al. 2015) and new types of uses are being explored, it would be peculiar if research was lagging far behind. The numbers in Figure 1 demonstrate how the field has grown, and provide empirical evidence for something that has been postulated in many studies (e.g., Fraustino, Liu \& Jin 2012; Ott \& Theunissen 2015).

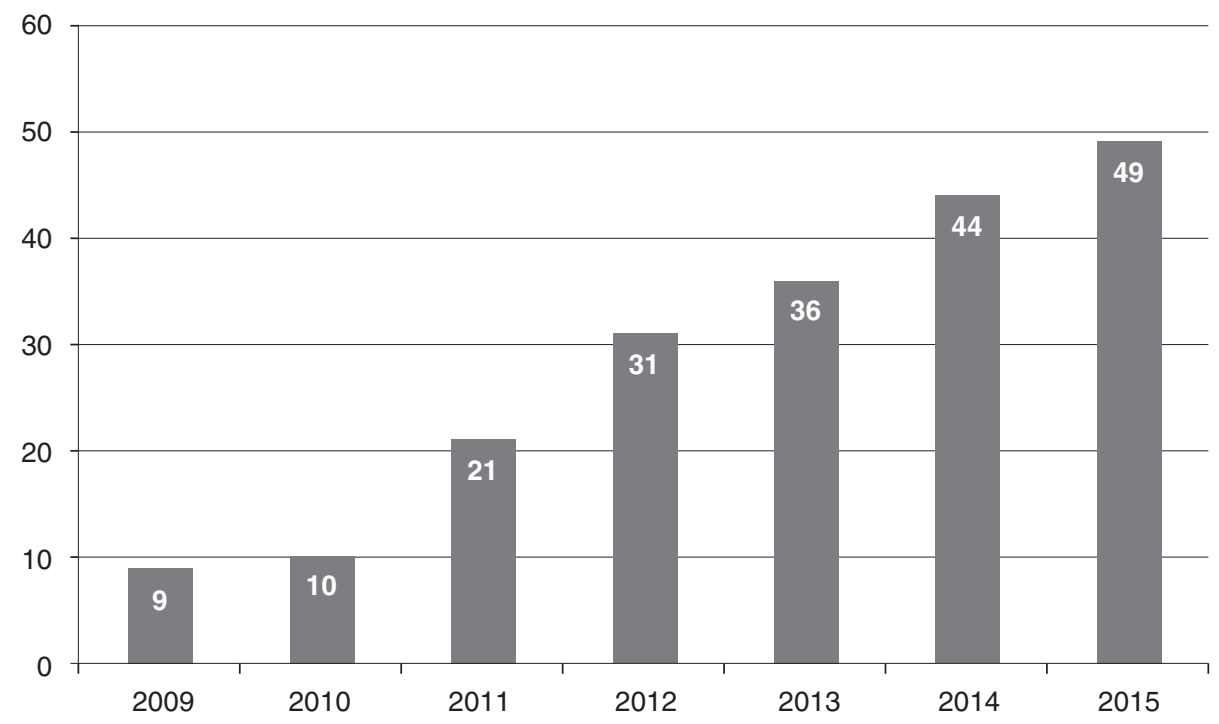

Figure 1. The number of journal articles 2009-2015 on social media, risk, and crisis communication $(\mathrm{N}=200)$

\section{Preventive risk communication, reactive crisis communication, and experiments}

Our review demonstrates that there is a rising interest in social media and crisis response (see Figure 2). A category of studies that first appeared in 2011 uses fictitious, experimental conditions to predict the outcome of social media choices in risk and crisis scenarios. For instance, the research shows that if the sender of a crisis message is an organisational leader rather than the organisation, the recipients are more likely to communicate the message further (Snoeijers, Poels \& Nicolay 2014). In addition, using personal voice and stories instead of a more official form of address reinforces the impression of interactivity (Park \& Cameron 2014). Most of these studies employ convenience sampling using students as subjects for the research, but a couple instead use population-wide samples 
that offer generalisability (e.g., Freberg 2012; Schultz, Utz \& Göritz 2011). Far fewer are the studies focusing on risk communication and social media. For this category, we have included studies that mainly use the concept of risk, and/or investigate situations or themes before or without a crisis having occurred. Figure 2 shows an overview of how the studies are distributed along the stages of risk, crisis, and fictitious scenarios.

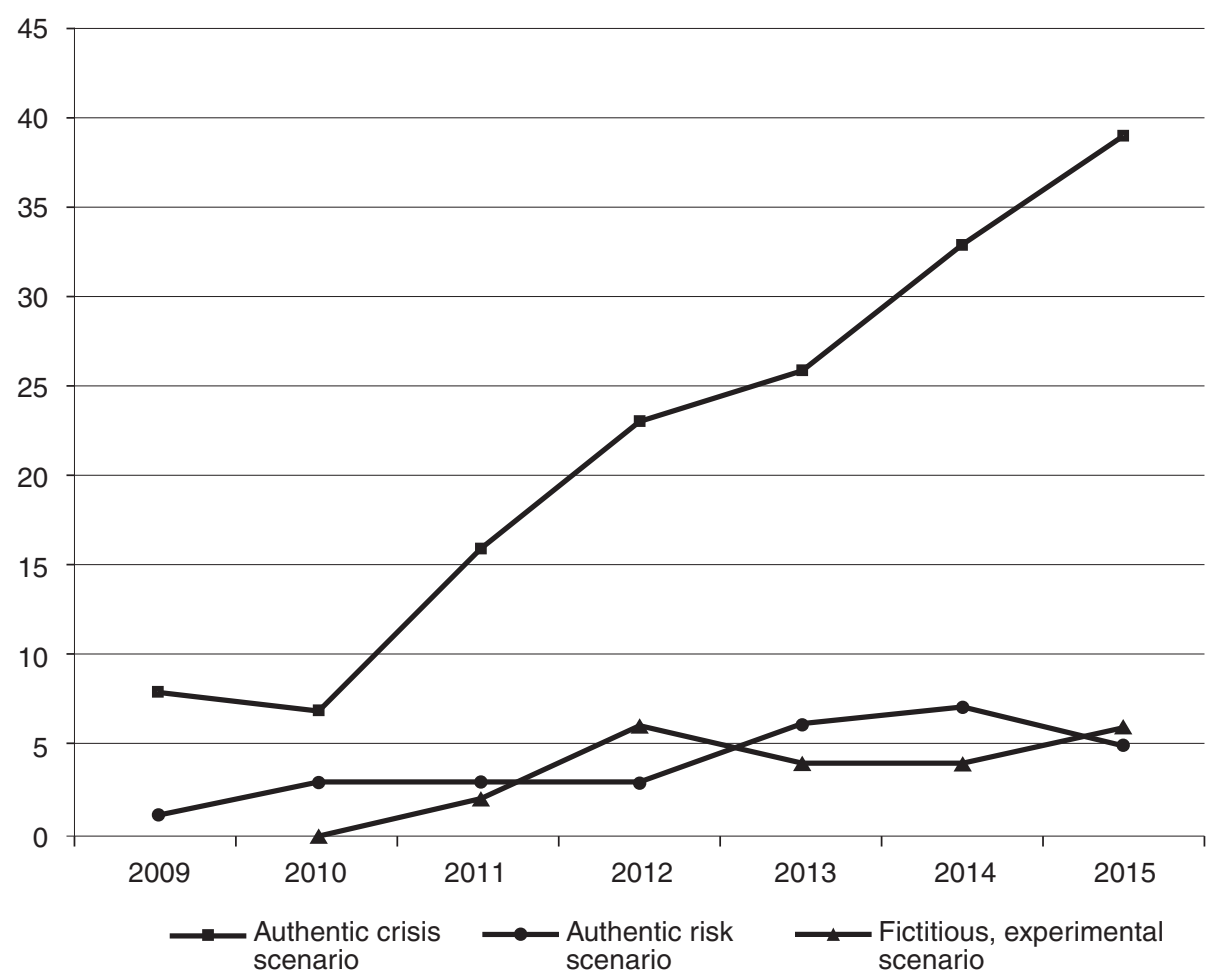

Figure 2. The number of journal articles 2009-2015 focusing on real-life risk scenarios, crisis scenarios, or experimental, fictitious scenarios

Note: A few articles feature both risk and crisis scenarios, and summed values exceed the population ( $\mathrm{N}=200)$.

\section{Social media platforms}

Our survey of which social media platforms the research focuses on confirms previous research findings (Fraustino, Liu \& Jin 2012) that Twitter dominates, ahead of Facebook and blogs (see Figure 3). In 2009 only two studies examined Twitter in risk and crisis contexts (e.g., Hughes \& Palen 2009), but in 2014 they peaked with twenty-eight.

Evidently, wikis represent both an under-used and under-studied social medium in view of its potential for rapid knowledge exchange across organisations and professions involved in risk and crisis contexts. When participation is not limited to a certain team beforehand, those who are most motivated and experienced can contribute. The "wisdom of crowds" is also needed to provide information and solve complex problems (Kaplan \& Haenlein 2014), not least when a crisis strikes. The rather large category of "other" platforms included studies of crisis maps (Plantin 2015) and Chinese platforms like Sina Weibo, Weixin, and Renren (Jiang et al. 2015; Wang 2014). 


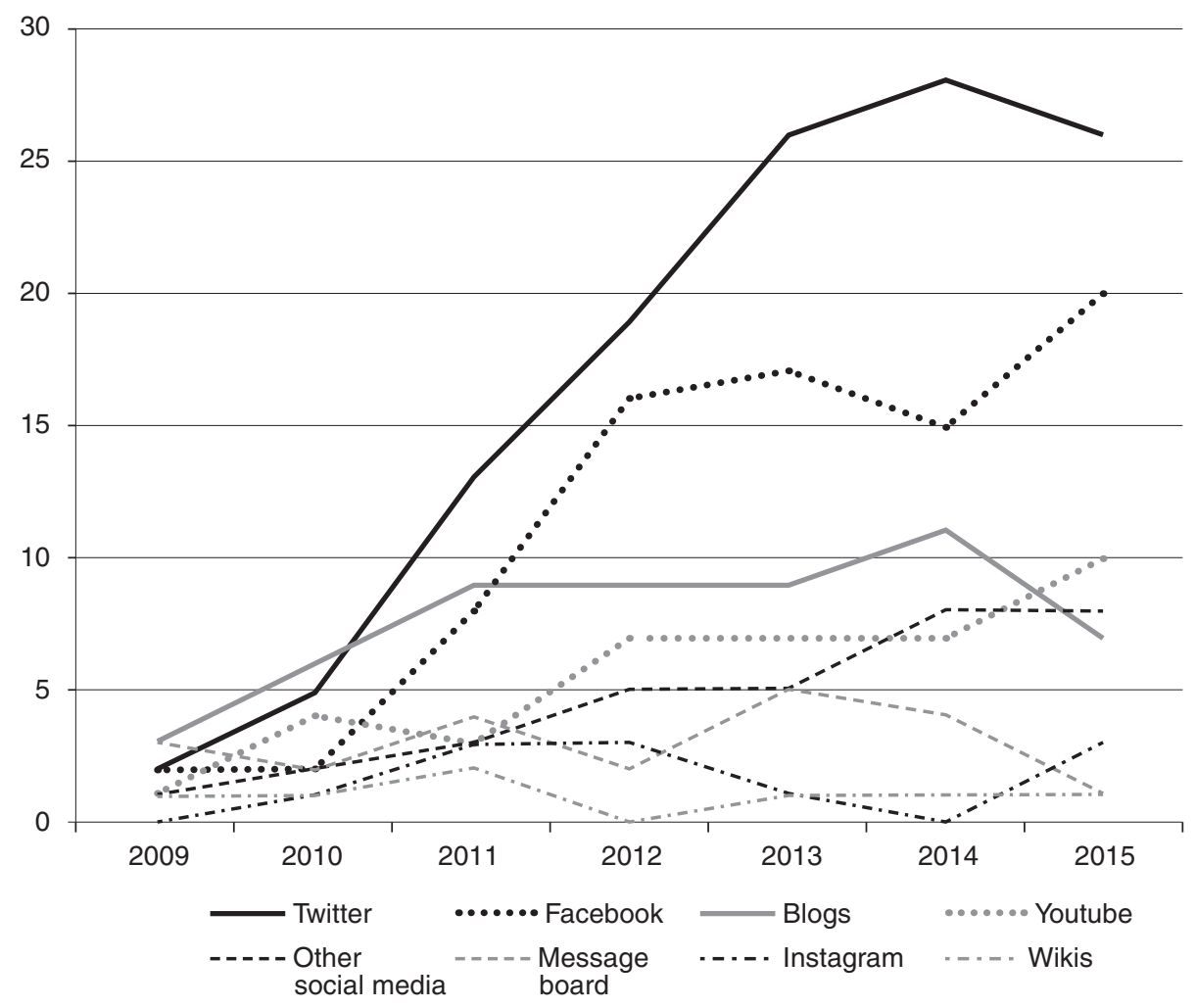

Figure 3. The number of journal articles 2009-2015 analysing particular social media

Note: Some articles focus on multiple social media, and summed values exceed the population $(\mathrm{N}=200)$.

Contrary to what Fraustino, Liu and Jin (2012) found in their review, our data does not demonstrate a lack of studies examining and comparing social media platforms (see Figure 4). Instead, there is increasing knowledge of the interplay of more than one social media platform and/or social media and traditional media (e.g., Freberg et al. 2013; Utz, Schultz \& Glocka 2013).

The research shows that social and traditional media channels are important for different reasons. For example, traditional media outlets are inherently considered more credible than social media sources, because of their perceived gatekeeping function and professionalism. Perceptions of the credibility of social media content vary more depending on who the source is, how recent the updates are (Westerman, Spence \& Van Der Heide 2014), as well as the communication style and tone (Park \& Cameron 2014). Yet, the credibility granted to traditional media and user-generated content varies depending on where social media users live. Pakistani social media users ascribe more legitimacy to user-generated content, and less to traditional media, compared to Western social media users, suggesting that there might be a different pattern of trust in developing countries (Murthy \& Longwell 2012). Moreover, social media like Twitter and Facebook are perceived to further extend the speed and reach of information-sharing during crises (Austin, Liu \& Jin 2012), whereas blogs in particular allow organisations to post in-depth information using plain language, receive feedback, and create identi- 


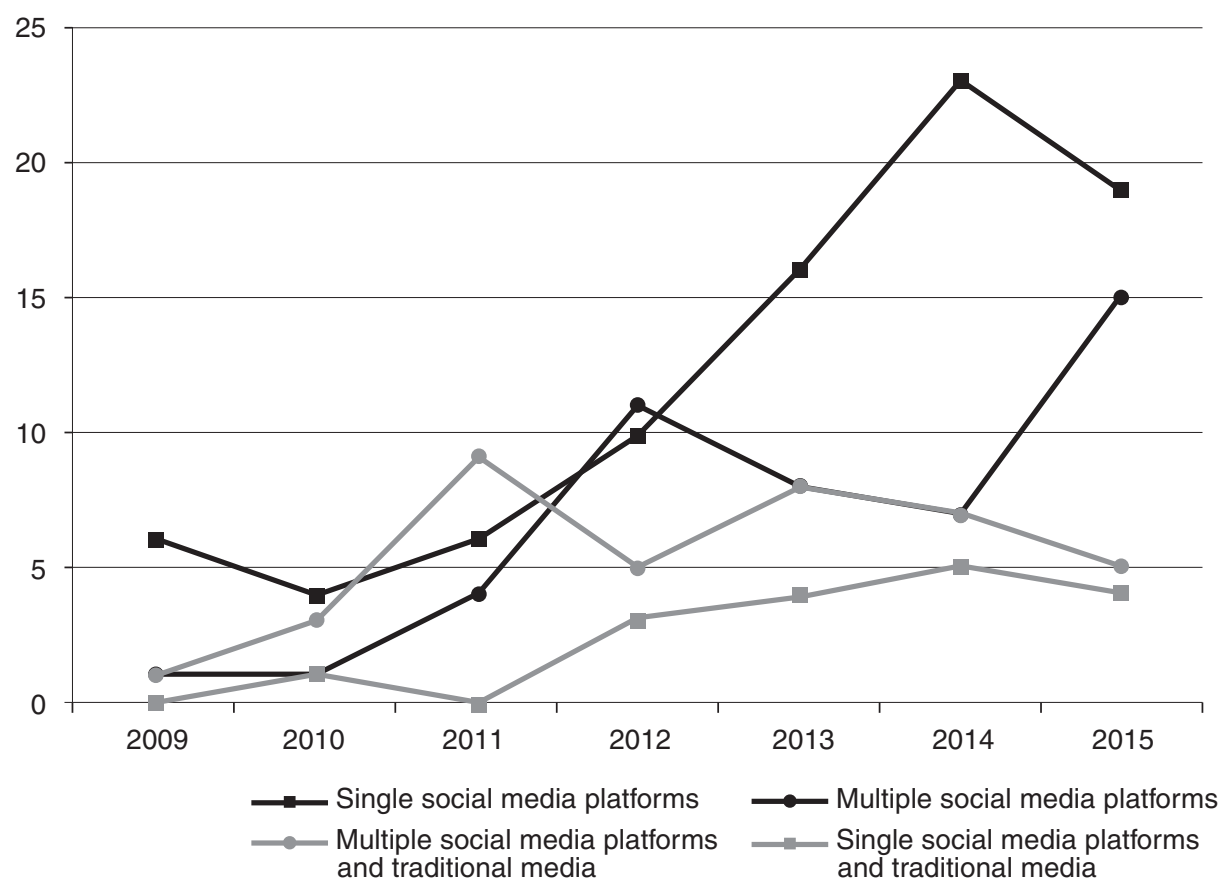

Figure 4. The number of journal articles 2009-2015 analysing single or multiple social media platforms, or combined with traditional media

fication (Park \& Cameron 2014). The speed and reach of information-sharing, however, will hinge on the degree to which the organisation is established in social media, and the audiences that use the platform.

\section{Social media users}

Furthermore, our data shows that the research covers a wide range of social media users. Our first category, featured in 99 articles, counts citizens and social media users in general. As shown in Table 1, the specific social media users that are studied most often are public and government institutions (e.g., Kavanaugh et al. 2012), followed by business/industry (e.g., Chewning 2015), and students (e.g., Westerman, Spence \& Van Der Heide 2014). Other actors studied are NGOs such as the Red Cross (e.g., Liu et al. 2012), journalists (e.g., Murthy \& Longwell 2012), public relations practitioners (e.g., Eriksson 2012), and educational institutions (Snoeijers, Poels \& Nicolay 2014).

Previous research has emphasised that public relations studies traditionally use theories and data that focus on the corporate sector, and that few studies within the specific research stream on risk and crisis communication are about public institutions (Olsson 2014). Our overview indicates that this is changing, or that the research focusing on risk, crisis, and social media is different since public institutions take centre stage slightly more often than corporate organisations. An implication of this would be that the field develops more theory that takes public authorities and community service as its priority. 
Table 1. Social media users studied (per cent of 200 analysed studies)

\begin{tabular}{lcr}
\hline Social media users & Number of studies & $\%$ \\
\hline Citizens / social media users in general & 99 & 49.5 \\
Public or government institution & 42 & 21 \\
Business organisation & 41 & 20.5 \\
Students & 25 & 12.5 \\
NGO & 24 & 12 \\
Media / Journalists & 23 & 11.5 \\
Public relations or communications staff & 11 & 5.5 \\
University / college & 5 & 2.5 \\
Other & 14 & 7 \\
\hline
\end{tabular}

\section{Geographical distribution and the digital divide}

It is clear that many parts of the world are studied in the field of risk, crisis, and social media in English-language journals. Research focusing on North America has a dominant position, followed by Western Europe and East Asia. Table 2 shows an overview.

Table 2. Geographical spread of social media users studied (per cent of 200 analysed studies)

\begin{tabular}{lcr}
\hline Region & Number of studies & $\%$ \\
\hline North America & 105 & 52.5 \\
Central America & 3 & 1.5 \\
South America & 1 & 0.5 \\
Western Europe & 50 & 25 \\
Eastern Europe & 2 & 1 \\
East Asia & 36 & 18 \\
Central Asia & 0 & 0 \\
South East Asia & 7 & 3.5 \\
South Asia & 5 & 2.5 \\
Middle East & 7 & 3.5 \\
Africa & 10 & 5 \\
Oceania & 11 & 5.5 \\
\hline
\end{tabular}

Among the 105 studies that had a North American focus, over 98 had a clear focus on either social media users or cases in the United States. We will not speculate too much on the reasons why our study captures so many fewer studies focusing on regions outside the US, Western Europe, and East Asia, and few or none using data from Eastern Europe, South America, and Central Asia. The reason may be our sample of English language journals, language barriers, or differences in internet and social media use. Yet only three studies focus on Canadian social media users or cases (Bergeron \& Friedman 2015; Saleem, Xu \& Ruths 2014), one of which also includes data from twenty-one other countries (Murthy \& Longwell 2012). A fourth reason for this identified gap may be differences regarding the research paradigms and concepts used. For instance, our impression is that research focusing on severe events in Africa and South America more often relate to development and conflict studies, and that the use of the terms risk and crisis are not widespread (e.g., Musa 2012). 
More knowledge is needed about the less researched regions. For instance, the only study focusing on Pakistani social media users shows that they, contrary to users in the West, rather tweet/retweet links to user-generated content than to editorial content (Murthy \& Longwell 2012). This is a reminder that the research results from the West are not necessarily valid in other regions.

Finally, we have investigated the extent to which research on risk, crisis, and social media takes into account the digital divide. The concept of the digital divide represents inequalities in a population - and between countries - regarding access to digital devices, internet access, and digital user knowledge (Mossberger, Tolbert \& Stansbury 2013). There were very few studies that drew attention to this important question.

Table 3. The number of studies addressing issues of social media access (per cent of 200 analysed studies)

\begin{tabular}{lcccccccccc}
\hline Issues of & \multicolumn{1}{c}{ Publication year } & \multicolumn{3}{c}{ Total } \\
social media access & $\mathbf{2 0 0 9}$ & $\mathbf{2 0 1 0}$ & $\mathbf{2 0 1 1}$ & $\mathbf{2 0 1 2}$ & $\mathbf{2 0 1 3}$ & $\mathbf{2 0 1 4}$ & $\mathbf{2 0 1 5}$ & $\mathbf{N}=\mathbf{2 0 0}$ & $\%$ \\
\hline High accessibility & 2 & 1 & 3 & 7 & 5 & 13 & 20 & 51 & 25.5 \\
Digital divide & 1 & 0 & 1 & 2 & 2 & 1 & 3 & 9 & 4.5 \\
Varying access & 0 & 0 & 0 & 1 & 2 & 0 & 4 & 7 & 3.5 \\
Disability and social media & 0 & 0 & 0 & 1 & 1 & 0 & 2 & 4 & 2 \\
\hline
\end{tabular}

Nine out of 200 studies mention the term "digital divide" (e.g., Murthy 2013), and an additional seven studies mentioned something about differences in ICT or social media access (e.g., Umihara \& Nishikitani 2013). Four studies of 200 mentioned the importance of reaching people with different disabilities with risk and crisis communication (e.g., Kent \& Ellis 2015). A larger number of studies $(\mathrm{N}=51)$ stress the accessibility of social media in positive terms. The broad lack of attention to boundaries in social media access and use is serious given that the research is all about risk and crisis communication, which often involves situations where citizens and communities and their health and welfare are at stake. It is crucial that risk and crisis information reach those in need, which justifies further investigation of this issue. Although few studies focus on issues of social media access, it is still a good sign that a fairly high number (30 per cent of 200 analysed studies) take into account both social and traditional media (see Figure 4). Partly because of the fragmented use of social and traditional media across demographics, the recommendation for risk and crisis communicators is to use multiple channels (Centers for Disease Control and Prevention 2014).

\section{Discussion and conclusion}

Between 2009 and 2015, an increasing number of studies dealing with risk, crisis, and social media were published. As shown above, most of the studies focused on crisis communication, more specifically, the use of Twitter, with Facebook placing second. About one-tenth of these studies used experimental scenarios and tested causal relations in social media crisis communication. By and large, the studies focused on citizens or undefined social media users. For the most part, the literature concerned real-life crisis communication in a North American setting. While we maintain that these traits and 
the presented numbers are interesting in themselves, they also indicate some areas that need more attention.

First, there is a need for more research on other types of social media than Twitter, Facebook, blogs, and YouTube, particularly since other types of platforms can provide further and better opportunities for risk and crisis planners. One unique study focused solely on wikis: Yates and Paquette (2011) presented a number of arguments for the usefulness of this social medium in times of crisis. A worthwhile direction for future research would be to examine wikis, and visuals such as editable maps, in crisis relief efforts. Still, we are aware that researchers also risk addressing the social media of yesterday, since technological development moves so fast. This, in turn, necessitates the identification of certain defining traits that are common across different social media, like visibility, editability, persistence, and association (Treem \& Leonardi 2012).

Second, as with much research, the studies about risk, crisis, and social media focuses mainly on the United States, followed by Western Europe and East Asia. Thus, our knowledge of how social media is used and understood in connection with risks and crises in other cultures is limited. Given that social media users on a large continent (South America) and in other major regions are largely overlooked, it is important to extend the research foci to include non-Western contexts and countries in the South. Otherwise, this stream of research becomes too particularistic and Western-centred without even demonstrating an awareness of these limitations. Risk and crisis situations are indeed global, and social media use is growing worldwide. For instance, there are 103 million active social media accounts in Africa, and nearly 197 million in South America (Kemp 2015). A way forward would be to further explore risks and crises as transboundary phenomena, realising that some boundaries are reproduced in a Euro-American research tradition, and that these boundaries are not only national, but separate regions and continents. The approach to risk and crisis transboundary phenomena should include the design of the research and its geographical focus. Some conceptualisations of risk and crisis can help facilitate a cross-cultural focus, of which a few were raised in the theory chapter.

Thirdly, a rather small part of the literature focuses on risk communication and social media. We can only speculate as to why crisis scenarios are studied much more often. Crises may be found more practical to study than risk situations in that they are perceived to be temporally and spatially limited events (Berthod, Müller-Seitz \& Sydow 2013). It might also be easier to get funding for the research, since crises receive much attention, raise questions about accountability and improvement, and prompt the organisations involved to protect their reputation. As a less-studied area, risk communication and social media make up a fruitful avenue for future research. Here, for instance, would be an excellent opportunity for practitioners and researchers alike to put insight from issues management into use. As mentioned, issues management could be thought of as a foresight-orientated, proactive part of public relations (Heath \& Palenchar 2008). In this regard, social media can be a listening post, but also a place where organisations can participate in dialogue with engaged stakeholders and risk bearers, and float suggestions before implementing them on a full scale. Through social media, concerns can be picked up and addressed.

Fourth, an important finding of the article is that there is so little attention being given to a notion like the digital divide, and to other issues relating to the uneven use and reach of risk and crisis communication through social media. For the most part, the studies 
seem to take for granted that the stakeholders and risk bearers are online and engaged. Risk and crisis planners must, however, also address resource-poor stakeholders and communities. This then, gives us an opportunity to call for using social media in tandem with traditional media, and not to regard social media as a panacea for problems of risk and crisis (Kent 2010; Kent, Saffer \& Pop 2013). There are, for instance, many more people who have access to the older cell phone features like text messaging compared with web features requiring a smartphone with an internet subscription (Kemp 2015). This makes us believe that mass text messages can effectively complement the Web 2.0 social media in times of crisis. This option, and several non-digital alternatives, need to be studied further. Also on the topic of access, only four studies mentioned people with disabilities and their use of social media in risk and crisis situations. In line with the UN convention on the rights of persons with disabilities, several nations have laws requiring that public authorities should promote universally accessible ICT solutions (UN General Assembly 2007) including social media platforms. An untapped venue for future research would thus be to study how social media in risk or crisis situations meets, or needs improvement in order to meet, the information needs of these groups.

Limitations: given that we solely focused on research in English, our review does not claim to cover all research in the area, and complementary reviews, including more languages, are needed. Our systematic review has also incorporated several themes, which implies that each one can only be dealt with briefly. Given this limitation, we want to encourage more reviews that go into one or more of the issues in greater depth. Selected themes could be the recent experimental studies and causal relationships in social media crisis communications, or non-Western research results and how they contrast with some of the Western research.

\section{References}

Alexander, David E. (2014). Social Media in Disaster Risk Reduction and Crisis Management. Science and Engineering Ethics, 20(3): 717-733.

Austin, Lucinda; Liu, Brooke Fisher \& Jin, Yan (2012). How Audiences seek out Crisis Information: Exploring the Social-mediated Crisis Communication Model. Journal of Applied Communication Research, 40(2): 188-207.

Bergeron, Caroline \& Friedman, Daniela B. (2015). Developing an Evaluation Tool for Disaster Risk Messages. Disaster Prevention and Management: An International Journal, 24(5): 570-582.

Berthod, Olivier; Müller-Seitz, Gordon \& Sydow, Jörg (2013). Interorganizational Crisis Management, pp. 139-152 in Thießen, Ansgar (ed.) Handbuch Krisenmanagement. Wiesbaden: Springer VS.

Boin, Arjen; Hart, Paul; Stern, Eric M. \& Sundelius, Bengt (2005). The Politics of Crisis Management: Public Leadership Under Pressure. Beverly Hills, CA: Sage.

Boin, Arjen; Rhinard, Mark \& Ekengren, Magnus (2014). Managing Transboundary Crises: The Emergence of European Union Capacity. Journal of Contingencies and Crisis Management, 22(3): 131-142.

Bowe, Brian J. \& Wohn, Donghee Yvette (2015). Are there Generational Differences?: Social Media Use and Perceived Shared Reality. Proceedings of the 2015 International Conference on Social Media \& Society. Toronto, Ontario, Canada: ACM, 1-5.

Centers for Disease Control and Prevention (2014). Crisis and Emergency Risk Communication: 2014 edition. Available at: http://emergency.cdc.gov/cerc/resources/pdf/cerc_2014edition

Chewning, Lisa V. (2015). Multiple Voices and Multiple Media: Co-constructing BP's Crisis Response. Public Relations Review, 41(1): 72-79.

\section{Acknowledgements}

This research was financed by The Research Council of Norway and its programme Societal Security (SAMRISK II). 
Duggan, Maeve; Ellison, Nicole B.; Lampe, Cliff; Lenhart, Amanda \& Madden, Mary (2015). Social Media Update 2014. Pew Research Center. Available at: http://www.pewinternet.org/files/2015/01/PI_SocialMediaUpdate20144.pdf

Eriksson, Mats (2012). On-line Strategic Crisis Communication: In Search of a Descriptive Model Approach. International Journal of Strategic Communication, 6(4): 309-327.

Falkheimer, Jesper (2013). Transboundary and Cultural Crisis Communication, pp. 211-223 in Thießen, Ansgar (ed.) Handbuch Krisenmanagement. Wiesbaden: Springer Fachmedien Wiesbaden.

Fraustino, Julia Daisy; Liu, Brooke \& Jin, Yan (2012). Social Media Use during Disasters: A Review of the Knowledge Base and Gaps. College Park, MD: U.S. Department of Homeland Security. Available at: http://www.start.umd.edu/sites/default/files/files/publications/START_SocialMediaUseduringDisasters_LitReview.pdf

Freberg, Karen (2012). Intention to Comply with Crisis Messages Communicated via Social Media. Public Relations Review, 38(3): 416-421.

Freberg, Karen; Saling, Kristin; Vidoloff, Kathleen G. \& Eosco, Gina (2013). Using Value Modeling to Evaluate Social Media Messages: The Case of Hurricane Irene. Public Relations Review, 39(3): 185-192.

Gender and Disaster Network (2008). The Gender and Disaster Sourcebook. London: GDN. Available at: https://www.gdnonline.org/sourcebook/

Grant, Maria J. \& Booth, Andrew (2009). A Typology of Reviews: An Analysis of 14 Review Types and Associated Methodologies. Health Information \& Libraries Journal, 26(2): 91-108.

Gunaratne, Shelton A. (2009). Emerging Global Divides in Media and Communication Theory: European Universalism versus Non-Western Reactions. Asian Journal of Communication, 19(4): 366-383.

Heath, Robert L. \& Palenchar, Michael (2008). Strategic Issues Management: Organizations and Public Policy Challenges. London: Sage.

Hilgartner, Stephen (1992). The Social Construction of Risk Objects, pp. 39-53 in Short, James F. \& Clarke, Lee (eds.) Organizations, Uncertainties, and Risk. Boulder: Westview Press.

Hogan, Bernie \& Quan-Haase, Anabel (2010). Persistence and Change in Social Media. Bulletin of Science, Technology \& Society, 30(5): 309-315.

Hughes, Amanda Lee \& Palen, Leysia (2009). Twitter Adoption and Use in Mass Convergence and Emergency Events. International Journal of Emergency Management, 6(3/4): 248-260.

Jiang, Jing; Huang, Yi-Hui; Wu, Fang; Choy, Hiu-Ying \& Lin, Di (2015). At the Crossroads of Inclusion and Distance: Organizational Crisis Communication During Celebrity-endorsement Crises in China. Public Relations Review, 41(1): 50-63.

Jin, Yan \& Liu, Brooke Fisher (2010). The Blog-mediated Crisis Communication Model: Recommendations for Responding to Influential External Blogs. Journal of Public Relations Research, 22(4): 429-455.

Jin, Yan, Liu, Brooke Fisher \& Austin, Lucinda L. (2014). Examining the Role of Social Media in Effective Crisis Management: The Effects of Crisis Origin, Information Form, and Source on Publics' Crisis Responses. Communication Research, 41(1): 74-94.

Kaplan, Andreas \& Haenlein, Michael (2014). Collaborative Projects (Social Media Application): About Wikipedia, the Free Encyclopedia. Business Horizons, 57(5): 617-626.

Kavanaugh, Andrea L.; Fox, Edward A.; Sheetz, Steven D.; Yang, Seungwon, et al. (2012). Social Media Use by Government: From the Routine to the Critical. Government Information Quarterly, 29(4): 480-491.

Kemp, Simon (2015). Digital, Social and Mobile in 2015. We Are Social. Available at: http://wearesocial.net/ blog/2015/01/digital-social-mobile-worldwide-2015/

Kent, Michael L (2010). Directions in Social Media for Professionals and Scholars, pp. 643-656 in Heath, Robert L. (ed.) The SAGE Handbook of Public Relations. Thousand Oaks, CA: Sage.

Kent, Michael L.; Saffer, Adam \& Pop, Rebeca (2013). Where Will Technology Take Us? New Directions in Social Media: A White Paper 2013. Norman, OK: University of Oklahoma.

Kent, Mike \& Ellis, Katie (2015). People with a Disability and New Disaster Communications: Access and the Social Media Mash-up. Disability \& Society, 30(3): 419-431.

Klinke, Andreas \& Renn, Ortwin (2002). A New Approach to Risk Evaluation and Management: Risk-based, Precaution-based, and Discourse-based Strategies. Risk Analysis, 22(6): 1071-1094.

Krippendorff, Klaus \& Bock, Mary Angela (2008). The Content Analysis Reader. Thousand Oaks, CA: Sage.

Liu, Brooke Fisher; Jin, Yan \& Austin, Lucinda L (2013). The Tendency to Tell: Understanding Publics' Communicative Responses to Crisis Information Form and Source. Journal of Public Relations Research, 25(1): 51-67.

Liu, Brooke Fisher; Jin; Yan; Briones, Rowena \& Kuch, Beth (2012). Managing Turbulence in the Blogosphere: Evaluating the Blog-mediated Crisis Communication Model with the American Red Cross. Journal of Public Relations Research, 24(4): 353-370.

Mossberger, Karen; Tolbert, Caroline J. \& Stansbury, Mary (2013). Virtual Inequality: Beyond the Digital Divide. Washington, DC: Georgetown University Press. 
Murthy, Dhiraj (2013). New Media and Natural Disasters. Information, Communication \& Society, 16(7): 1176-1192.

Murthy, Dhiraj \& Longwell, Scott A. (2012). Twitter and Disasters. Information, Communication \& Society, 16(6): 837-855.

Musa, Aliyu Odamah (2012). Socio-economic Incentives, New Media and the Boko Haram Campaign of Violence in Northern Nigeria. Journal of African Media Studies, 4(1): 111-124.

Norris, Pippa (2001). Digital Divide: Civic Engagement, Information Poverty, and the Internet Worldwide. Cambridge University Press.

Olsson, Eva-Karin (2014). Crisis Communication in Public Organisations: Dimensions of Crisis Communication Revisited. Journal of Contingencies and Crisis Management, 22(2): 113-125.

Olsson, Eva-Karin (2015). Transboundary Crisis Networks: The Challenge of Coordination in the Face of Global Threats. Risk Management, 17(2): 91-108.

Ott, Larissa \& Theunissen, Petra (2015). Reputations at Risk: Engagement During Social Media Crises. Public Relations Review, 41(1): 97-102.

Paine, Katie Delahaye (2007). How to Measure Social Media Relations: The More Things Change, the More they Remain the Same. Available at: http://www.instituteforpr.org/wp-content/uploads/How_to_Measure_Blogs.pdf

Palenchar, Michael J. (2009). Historical Trends of Risk and Crisis Communication, pp. 31-52 in Heath, Robert L. \& O'Hair, Dan (eds.) Handbook of Risk and Crisis Communication. New York: Routledge.

Park, Hyojung \& Cameron, Glen T. (2014). Keeping it Real: Exploring the Roles of Conversational Human Voice and Source Credibility in Crisis Communication via Blogs. Journalism \& Mass Communication Quarterly, 91(3): 487-507.

Plantin, Jean-Christophe (2015). The Politics of Mapping Platforms: Participatory Radiation Mapping after the Fukushima Daiichi Disaster. Media, Culture \& Society, 37(6): 904-921.

Procopio, Claire H. \& Procopio, Steven T. (2007). Do You Know What It Means to Miss New Orleans? Internet Communication, Geographic Community, and Social Capital in Crisis. Journal of Applied Communication Research, 35(1): 67-87.

Ruggiero, Aino \& Vos, Marita (2014). Social Media Monitoring for Crisis Communication: Process, Methods and Trends in the Scientific Literature. Online Journal of Communication and Media Technologies, 4(1): 105-130.

Saleem, Haji Mohammad; Xu, Yishi \& Ruths, Derek (2014). Novel Situational Information in Mass Emergencies: What does Twitter Provide? Procedia Engineering, 78(155-164).

Schultz, Friederike, Utz, Sonja \& Göritz, Anja (2011). Is the Medium the Message? Perceptions of and Reactions to Crisis Communication via Twitter, Blogs and Traditional Media. Public Relations Review, 37(1): 20-27.

Simon, Tomer; Goldberg, Avishay \& Adini, Bruria (2015). Socializing in Emergencies - A Review of the Use of Social Media in Emergency Situations. International Journal of Information Management, 35(5): 609-619.

Smith, Brian G. (2010). Socially Distributing Public Relations: Twitter, Haiti, and Interactivity in Social Media. Public Relations Review, 36(4): 329-335.

Snoeijers, Erik M.; Poels, Karolien \& Nicolay, Colombine (2014). \#universitycrisis: The Impact of Social Media Type, Source, and Information on Student Responses Toward a University Crisis. Social Science Computer Review, 32(5): 647-661.

Sweetser, Kaye D. \& Metzgar, Emily (2007). Communicating During Crisis: Use of Blogs as a Relationship Management Tool. Public Relations Review, 33(3): 340-342.

Thiede, Brian C. \& Brown, David L. (2013). Hurricane Katrina: Who Stayed and Why? Population Research and Policy Review, 32(6): 803-824.

Treem, Jeffrey \& Leonardi, Paul (2012). Social Media Use in Organizations: Exploring the Affordances of Visibility, Editability, Persistence, and Association. Communication Yearbook, 36(143-189).

Umihara, Junko \& Nishikitani, Mariko (2013). Emergent use of Twitter in the 2011 Tohoku Earthquake. Prehospital and Disaster Medicine, 28(05): 434-440.

UN General Assembly (2007). Convention on the Rights of Persons with Disabilities. A/RES/61/106. Available at: http://www.un-documents.net/a61r106.htm

Utz, Sonja; Schultz, Friederike \& Glocka, Sandra (2013). Crisis Communication Online: How Medium, Crisis Type and Emotions Affected Public Reactions in the Fukushima Daiichi Nuclear Disaster. Public Relations Review, 39(1): 40-46.

Veil, Shari R.; Buehner, Tara \& Palenchar, Michael J (2011). A Work-in-Process Literature Review: Incorporating Social Media in Risk and Crisis Communication. Journal of Contingencies and Crisis Management, 19(2): 110-122.

Wang, Xuequn (2014). How do People Participate in Social Network Sites after Crises? A Self-determination Perspective. Social Science Computer Review, 32(5): 662-677. 
Joel Rasmussen \& Øyvind Ihlen

Westerman, David; Spence, Patric R. \& Van Der Heide, Brandon (2014). Social Media as Information Source: Recency of Updates and Credibility of Information. Journal of Computer-Mediated Communication, 19(2): 171-183.

Wu, Shaomei; Hofman, Jake M.; Mason, Winter A. \& Watts, Duncan J (2011). Who Says What to Whom on Twitter. Proceedings of the 20th International Conference on World Wide Web. Hyderabad, India: ACM, 705-714.

$\mathrm{Xu}$, Jie \& Wu, Yiye (2015). Using Twitter in Crisis Management for Organizations Bearing Different Countryof-Origin Perceptions. Journal of Communication Management, 19(3): 239-253.

Yates, Dave \& Paquette, Scott (2011). Emergency Knowledge Management and Social Media Technologies: A Case Study of the 2010 Haitian Earthquake. International Journal of Information Management, 31(1): 6-13.

Zickuhr, Kathryn (2013). Who's Not Online and Why. Pew Internet and American Life Project. Available at: http://www.pewinternet.org/files/old-media//Files/Reports/2013/PIP_Offline\%20adults_092513_PDF.pdf

JOEL RASMUSSEN, Senior Lecturer, Media and Communication Studies, Örebro University, joel.rasmussen@oru.se

ØYVIND IHLEN, Professor, Department of Media and Communication, University of Oslo, oyvind.ihlen@media.uio.no 


\section{Appendix}

1. Asia Pacific Media Educator

2. Australian Journal of Communication

3. Australian Journal of Emergency Management

4. Australian Journal of Public Administration

5. Bulletin of the American Society for Information Science and Technology (Online)

6. Business Horizons

7. China Media Research

8. Chinese Journal of Communication

9. Communication Research

10. Communication \& Society / Comunicación y Sociedad

11. Communication Studies

12. Communications of the IIMA

13. Computer Supported Cooperative Work (CSCW)

14. Computers in Human Behavior

15. Corporate Communications

16. Corporate Reputation Review

17. Critical Studies on Terrorism

18. Culture Unbound

19. Disability \& Society

20. Digital Creativity

21. Disaster Prevention and Management

22. Disasters

23. Discourse \& Society

24. Ecquid Novi: African Journalism Studies

25. Environmental Communication

26. European Journal of Communication

27. First Monday

28. Florida Communication Journal

29. Food Control

30. Food Policy

31. Food Quality and Preference

32. Global Media \& Communication

33. Global Media Journal

34. Government Information Quarterly

35. Health Communication

36. Health, Risk \& Society

37. Infectious Diseases of Poverty

38. Information, Communication \& Society

39. Interactions: Studies in Communication \& Culture

40. International Communication Gazette

41. International Journal of Advancements in Computing Technology

42. International Journal of Communication

43. International Journal of Food System Dynamics

44. International Journal of Emergency Management

45. International Journal of Human-Computer Studies

46. International Journal of Information Management

47. International Journal of Information Systems for Crisis Response and Management (IJISCRAM)

48. International Journal of Japanese Sociology

49. International Journal of Media and Cultural Politics

50. International Journal of Strategic Communication

51. International Journal of Web Information Systems

52. Jàmbá: Journal of Disaster Risk Studies
53. Journal of African Media Studies

54. Journal of Applied Communication Research

55. Journal of Broadcasting \& Electronic Media

56. Journal of Business Case Studies (Online)

57. Journal of Business Research

58. Journal of Communication Management

59. Journal of Communication in Healthcare

60. Journal of Comparative Policy Analysis: Research and Practice

61. Journal of Computer-Mediated Communication

62. Journal of Contingencies and Crisis Management

63. Journal of Health Communication

64. Journal of Homeland Security \& Emergency Management

65. Journal of Map \& Geography Libraries

66. Journal of Media Practice

67. Journal of Middle East Media

68. Journal of Public Affairs

69. Journal of Public Relations Research

70. Journal of Risk Research

71. Journal of Technology in Human Services

72. Journalism \& Mass Communication Quarterly

73. Journalism Studies

74. Management Communication Quarterly

75. Management Research Review

76. Mass Communication \& Society

77. Media International Australia

78. Media, Culture \& Society

79. MIS Quarterly

80. Natural Hazards

81. New Media \& Society

82. Newspaper Research Journal

83. Online Journal of International Case Analysis

84. PLoS ONE

85. Policing and Society

86. Policy \& Internet

87. Prehospital and Disaster Medicine

88. Public Health

89. Public Relations Journal

90. Public Relations Review

91. Public Understanding of Science

92. Procedia Engineering

93. Psychiatry Research

94. Queensland Review

95. Revista Latina de Comunicación Social

96. Risk Analysis

97. Romanian Journal of Journalism

\& Communication

98. Science Communication

99. Social Science Computer Review

100. Technical Communication Quarterly

101. Technological Forecasting and Social Change

102. Television \& New Media

103. The Australian Library Journal

104. The Internet and Higher Education

105. The Journal of Business Strategy

106. Vaccine 